\title{
Nanosized Noble Metals Intercalated in Clay as Catalysts for Selective Hydrogenation
}

\author{
Manikandan DHANAGOPAL ${ }^{1,2}$, DURAISWAMI Divakar ${ }^{1,3}$, Rupa A. VALENTINE ${ }^{1}$, \\ Mangalaraja RAMALINGA VISWANATHAN ${ }^{2}$, Sivakumar THIRIPURANTHAGAN ${ }^{1, *}$ \\ ${ }^{1}$ Catalysis Laboratory, Department of Chemical Engineering, A.C. College of Technology, Anna University, Chennai 600025 , India \\ ${ }^{2}$ Advanced Ceramic and Nanotechnology Laboratory, Department of Materials Engineering, Faculty of Engineering, \\ University of Concepcion, Concepcion 407-0417, Chile \\ ${ }^{3}$ Department of Chemical Engineering, Faculty of Science and Technology, University of Basque Country, 48940 Leioa, Bizkaia, Spain
}

\begin{abstract}
The use of clay minerals in the synthesis of nanosized noble metal particles to give increased catalytic activity was investigated. Nanosized platinum and ruthenium catalysts intercalated in clay (montmorillonite/hectorite) were synthesised and their catalytic activity was evaluated for the selective hydrogenation of three different $\alpha, \beta$-unsaturated aldehydes, namely, crotonaldehyde, cinnamaldehyde, and citral, in a gas phase microreactor. The metal nano-sol was prepared by the chemical reduction of its precursor by the micellar technique in the presence of cetyl trimethyl ammonium bromide (CTAB), and the micelle stabilized metal particles were intercalated in the clay mineral by ion exchange. TEM micrographs of the catalyst particles showed that the metal particles were in the nanometre range. The average diameters of the particles were $1-25 \mathrm{~nm}$. The effects of temperature, metal loading, and hydrogen flow rate on the catalytic activity and selectivity for $\alpha, \beta$ - unsaturated alcohol were studied. The results were correlated with the structural properties of the catalysts. The products formed in each reaction over the different catalysts showed that the catalysts were very active for hydrogenation, and the selectivity for the desired product, namely, $\alpha, \beta$-unsaturated alcohol, was good. The metal catalysts intercalated in montmorillonite showed better selectivity than that in hectorite because of its higher acidity. Increased selectivity for $\alpha, \beta$-unsaturated alcohol was observed with increased flow rate of hydrogen.
\end{abstract}

Key words: selective hydrogenation; nano-particle; platinum; ruthenium; intercalated montmorillonite or hectorite; vapor phase reaction CLC number: O643 Document code: A

The synthesis of metal nano-particles was first reported by Boutonnet et al. [1] in the early eighties. Metal nano-particles are of wide interest in the catalysis industry because of their large surface area, and they have some interesting properties that are different from those of bulk metal solids [2,3]. Among these, increased catalytic activity has been reported with nano-particles, which was correlated with their sizes and shapes [4,5]. As the size of the particle approaches a few nanometres, the surface area to volume ratio dramatically increases. The increased surface area of the nano-catalyst results in more interaction between the catalyst and reactants, which leads to a higher conversion. Surface atoms that are in corners and edges also dramatically increase when the size is decreased to below a few nanometres.

A promising method to prepare metal nano-clusters is by chemical synthesis in a solution with a dispersing agent to produce fine metal particles. Nano-particles are formed upon reduction of the salts of the corresponding metals in the presence of substrates that stabilize the colloidal particles in the solutions. The methods generally use reduction by radiation or chemical reduction [6] in an aqueous solution with [7] and without stabilizing polymers [8-10], and the chemical or photo-reduction of surfactant micelles [11-13]. The colloidal stability, particle size, and catalytic properties of the nano-particles are strongly dependent on the specific method and experimental conditions used.

Polymer stabilized metal particles with a narrow particle size distribution have been used as catalysts in selective hydrogenation. Pt catalysts stabilized by poly-( $N$-vinyl-2pyrrolidone) with a particle size of $1.1 \mathrm{~nm}$ was reported as highly active and selective in the hydrogenation of cinnamaldehyde [14]. A polymer resin stabilized Pt catalyst was also found to be a good catalyst for the hydrogenation of citral [15]. Although these catalysts were active and selective for the hydrogenation of unsaturated aldehydes, their industrial use was limited because of the difficulty in separating the catalysts for recycling. Therefore, attempts were made to immobilize these colloidal metal particles from the aqueous solution onto the surface of solid supports [16-18]. The interlayer space available in clay minerals was shown to be a very good phase that hosted finely dispersed metal

Received date: 29 March 2010.

*Corresponding author. Tel: +91-44-22203534 Extn. 24; E-mail: sivakumar@annauniv.edu Foundation item: Supported by FONDECYT, Chile-Post Doctorate-2010 Project (3100010). English edition available online at ScienceDirect (http://www.sciencedirect.com/science/journal/18722067). 
nano-catalysts without aggregation [19-24]. The use of such catalysts in selective hydrogenation reactions was beneficial in terms of both activity and selectivity $[25,26]$.

$\alpha, \beta$-unsaturated alcohols find applications in the chemical, pharmaceutical, food, flavors, and fragrance industries. It will be useful to find new catalysts for the selective hydrogenation of $\alpha, \beta$-unsaturated aldehydes (namely cinnamaldehyde, crotonaldehyde, citral, etc.) that can give very high conversion and selectivity for the corresponding $\alpha, \beta$ unsaturated alcohols. Among the various parameters which govern the selectivity, the structure of the reactant is one of the more important [27]. Small molecules such as acrolein, crotonaldehyde, etc. yield their corresponding saturated aldehydes as final products because of the easy hydrogenation of the $\mathrm{C}=\mathrm{C}$ bond due to favorable thermodynamic and kinetic factors. However, in the case of larger unsaturated aldehydes, the steric effect due to the presence of substituents on the $\mathrm{C}=\mathrm{C}$ bond can influence product selectivity. A variety of catalytic systems have been reported for the selective hydrogenation of $\alpha, \beta$-unsaturated aldehydes in the liquid phase $[15,28,29]$. We have reported the selective hydrogenation of cinnamaldehyde and citral over noble metals catalysts intercalated in clay $[30,31]$. The liquid phase reaction has inherent limitations such as difficulty in handling high pressure, corrosive nature of the solvents, separation of the catalysts, lack of reusability, large amount of catalysts used, and disposal of the reaction wastes. Therefore, the chemical and pharmaceutical industries prefer vapor phase reactions. Thus, it is necessary to find a suitable catalyst system with high selectivity for the vapor phase hydrogenation of $\alpha, \beta$-unsaturated aldehydes. The literature on the vapour phase hydrogenation of $\alpha, \beta$-unsaturated aldehydes is scarce [32-34] because the high temperature in these hydrogenation reactions favour $\mathrm{C}=\mathrm{C}$ hydrogenation rather than $\mathrm{C}=\mathrm{O}$ hydrogenation. In this context, the investigation of selective hydrogenation of $\alpha, \beta$-unsaturated aldehydes in the vapor phase using a pulse reactor and metal nano-particle catalysts loaded in clay is important.

In this paper, we report the synthesis and characterization of the noble metals of $\mathrm{Pt}$ and $\mathrm{Ru}$ intercalated in montmorillonite and hectorite and their catalytic activity for the selective hydrogenation of $\alpha, \beta$-unsaturated aldehydes with different structures such as crotonaldehyde, cinnamaldehyde, and citral.

\section{Experimental}

\subsection{Synthesis of the catalysts}

A known amount of montmorillonite was first ion exchanged by stirring in $2 \mathrm{~mol} / \mathrm{L} \mathrm{NaCl}$ solution to ensure that all the exchangeable cations were $\mathrm{Na}^{+}$. Dried
Na-montmorillonite or Li-hectorite ( $3 \mathrm{~g}$ ) as received from Wako Pure Chemical Industries Ltd., Japan were separately dispersed in $200 \mathrm{ml}$ water and allowed to swell for about $6 \mathrm{~h}$ with continuous stirring. Platinum or ruthenium nanosol was prepared by adding the metal precursors (hexachloroplatinic acid or hexammineruthenium chloride, respectively) containing $1 \%$ or $2 \%$ metal in water in the presence of cetyltrimethylammonium bromide and stirred for $2 \mathrm{~h}$. The precursor in the micelles was reduced to the metallic state by the dropwise addition of an aqueous solution of $\mathrm{NaBH}_{4}$ $(0.05 \mathrm{~g}$ in $10 \mathrm{ml})$ and stirred for about $3 \mathrm{~h}$. Then the black colored metal nano-sol was added to the aqueous suspension of the clay and kept under vigorous stirring for about $24 \mathrm{~h}$. The ion exchange reaction of $\mathrm{Na}^{+}$in the case of montmorillonite and $\mathrm{Li}^{+}$in the case of hectorite with the cetyltrimethylammonium cation $\left(\mathrm{CTA}^{+}\right)$resulted in the formation of an organo-clay complex with the simultaneous intercalation of the Pt or Ru particles, respectively, into the internal of the (interlamellar) clay material $[35,36]$. The organo-clay samples (black in color) were washed thoroughly with ethanol and toluene to remove excess surfactant and air-dried. The different catalysts synthesized were named Pt-CTA-MM 1, Pt-CTA-MM 2, Ru-CTA-MM 1, Ru-CTA-MM 2, Pt-CTA-Hec 1, Pt-CTA-Hec 2, Ru-CTAHec 1, and Ru-CTA-Hec 2, where MM referred to montmorillonite, Hec referred to hectorite, CTA referred to cetyl trimethyl ammonium cation, and the number 1 and 2 indicated the metal loading in $\mathrm{wt} \%$.

\subsection{Physicochemical characterization}

All the reduced catalysts were characterized by X-ray diffraction (XRD) in the region of $2 \theta=1.0^{\circ}$ to $50^{\circ}$ (Philips X'pert X-ray diffractometer using $\mathrm{Cu} K_{\alpha}$ radiation of wave length $\lambda=0.154 \mathrm{~nm}$ ). For the transmission microscope analysis, the intercalated catalysts (black powder after reduction) were dispersed in isopropanol, and a drop of this dispersion was placed on a copper grid and TEM photographs were taken using a JEOL JEM-2010F to determine the size of the noble metal particles. The catalysts were also characterized by atomic absorption spectrophotometry (AAS) (Perkin Elmer 2380). The specific surface area of representative samples were determined by the BET method using nitrogen as adsorbate with a Quantachrome Nova 4200 e surface area analyser. The samples were degassed at $250{ }^{\circ} \mathrm{C}$ under vacuum $(<0.1 \mathrm{~Pa})$ for $2 \mathrm{~h}$ prior to the adsorption measurement.

\subsection{Catalytic activity in vapor phase hydrogenation}

Catalytic reaction experiments were carried out in the vapor phase with a flow microreactor equipped with an 
automated online analysis system described below.

A pyrex reactor $(20 \mathrm{~cm}$ length and $0.5 \mathrm{~cm}$ i.d.) was placed in a vertical furnace which can be heated to high temperature in a controlled manner. A thermocouple was inserted to give the temperature of the catalyst bed. The pulse reactor contained an injector port covered with a ribbon type heater to prevent the condensation of the reactant and also to serve as a preheating zone. The ribbon type heaters were also used to cover both the inlet and outlet of the reactor. The entire tubing was insulated with asbestos tape. The stainless steel tubings on both sides of the pulse reactor and the injection valve were heated to $270{ }^{\circ} \mathrm{C}$ to prevent condensation. The outlet of the reactor was connected to the inlet of a chromatographic column ApiezonT of the GC (Shimadzu 17A).

The reduced catalysts $(0.1 \mathrm{~g})$ placed in the microreactor were pretreated in flowing hydrogen $(40 \mathrm{ml} / \mathrm{min})$ at $200{ }^{\circ} \mathrm{C}$ for $1 \mathrm{~h}$ prior to catalytic reaction. The catalytic activity was evaluated by injecting $1.0 \mu \mathrm{l}$ of the reactant (crotonaldehyde or cinnamaldehyde or citral) at different temperatures from 100 to $200{ }^{\circ} \mathrm{C}$ in steps of $25{ }^{\circ} \mathrm{C}$ with different flow rates of hydrogen $(20-80 \mathrm{ml} / \mathrm{min})$. The products were separated and identified by online gas chromatographic analysis. The column temperature was kept at $200{ }^{\circ} \mathrm{C}$. Reagents and products were identified by comparison with standard samples. All the experiments were repeated at least twice, and the reproducibility was within $\pm 3 \%$. Blank experiments showed no catalytic activity due to the support under these conditions.

\section{Results and discussion}

\subsection{Characterization studies}

\subsubsection{XRD analysis}

The XRD patterns of Na-montmorillonite and Pt intercalated in montmorillonite (Pt-CTA-MM 1 and Pt-CTA-MM 2) previously reported by us [37] showed that the $d$ (001) reflection of Na-montmorillonite appeared at $2 \theta=6.1^{\circ}$, which corresponded to a $d$ spacing of $1.447 \mathrm{~nm}$, and this $2 \theta$ value was shifted to $2 \theta=1.5^{\circ}$ for the $\mathrm{CTA}^{+}$exchanged $\mathrm{Pt}$ montmorillonite catalysts, which corresponded to the $d$ spacing of $5.925 \mathrm{~nm}$ (Fig. 1).

The shift in the $2 \theta$ value of the $d(001)$ reflection to a lower value revealed that the basal spacing was increased by the incorporation of a bigger organic moiety in the interlamellar space that replaced $\mathrm{M}^{+}$. The remarkable increase in the $d$ spacing value to $5.925 \mathrm{~nm}$ after the intercalation of the $\mathrm{CTA}^{+}$cation into the interlayer space indicated the better swelling ability of the montmorillonite due to its higher CEC value than the other members in the smectite family. A small peak at $2 \theta=40^{\circ}$ indicated the presence of platinum

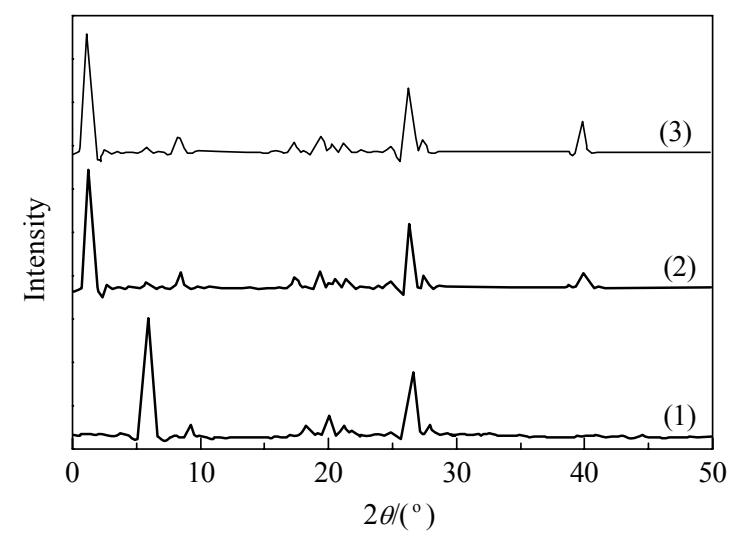

Fig. 1. XRD patterns of Na-MM (1), Pt-CTA-MM 1 (2), and Pt-CTA-MM 2 (3).

particles $(\operatorname{Pt}(111))$, and the intensity of this peak increased when the loading of platinum was increased (Fig. 1(b) and (c)). Furthermore, there was no shift in any other peak, which indicated that the exchange of $\mathrm{Na}^{+}$with $\mathrm{CTA}^{+}$along with the incorporation of platinum particles in the interlayer surface did not alter the basic lattice structure of montmorillonite. The ruthenium intercalated in montmorillonite catalysts also showed similar XRD patterns (Fig. 2) to that of the platinum intercalated in montmorillonite catalysts. A shift from $2 \theta=6.1^{\circ}(d$ spacing $1.447 \mathrm{~nm})$ to $2 \theta=1.5^{\circ}(d$ spacing $5.925 \mathrm{~nm}$ ) and the (111) peak of Ru observed at $2 \theta$ $=44.5^{\circ}$ confirmed the presence of ruthenium intercalated in the montmorillonite.

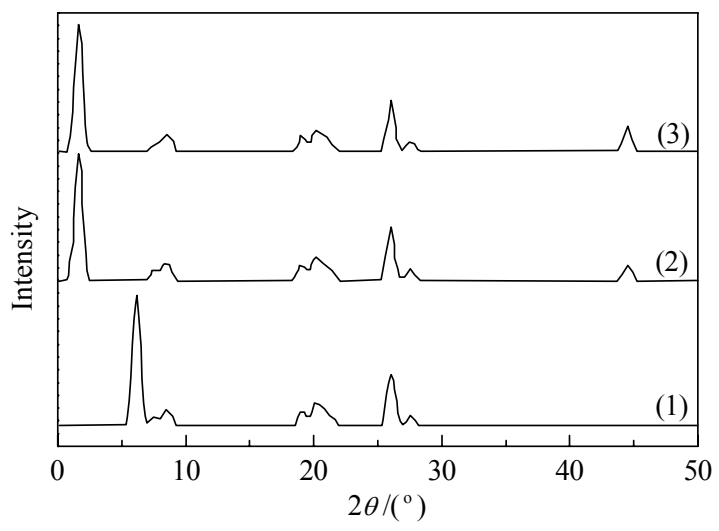

Fig. 2. XRD patterns of Na-MM (1), Ru-CTA-MM 1 (2), and Ru-CTA-MM 2 (3).

The XRD patterns of Li-hectorite is shown in Fig. 3, in which the first order reflection appeared at $2 \theta=7.4^{\circ}(1.19$ $\mathrm{nm})$. The same peak after the modification with the cationic surfactant $(\mathrm{CTAB})$ was shifted to $2 \theta=4.6^{\circ}(1.93 \mathrm{~nm})$. The increase in the basal spacing in hectorite was less when compared to montmorillonite. This was because of the lower CEC value of hectorite as compared to montmorillonite. The CEC value $(87 \mathrm{meq} / 100 \mathrm{~g}$ and $49 \mathrm{meq} / 100 \mathrm{~g}$ for 


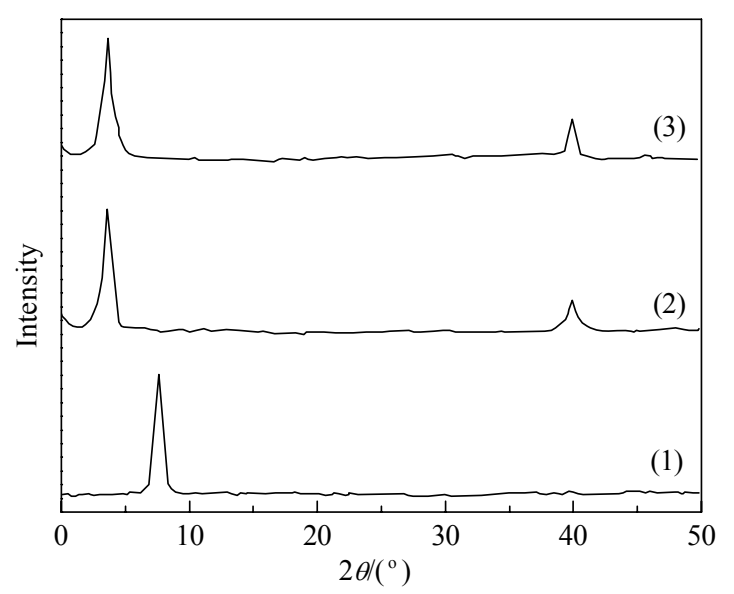

Fig. 3. XRD patterns of $\mathrm{Li}-\mathrm{Hec}$ (1), Pt-CTA-Hec 1 (2), and Pt-CTA-Hec 2 (3).

montmorillonite and hectorite, respectively) determines the amount of exchange of the surfactant cation $\left(\mathrm{CTA}^{+}\right)$, which in turn causes the increase in basal spacing. More exchange of the bulky organic cation gives a larger basal spacing. The XRD data also revealed that the lattice structure of the clay minerals was not affected by the introduction of metal particles and the surfactant micelle.

\subsubsection{TEM analysis}

TEM images of platinum and ruthenium intercalated in montmorillonite are shown in Fig. 4. A good and uniform dispersion was obtained with almost all the catalysts, which was previously reported by us $[37,38]$. The average diameters of the particles are reported in Table 1. The diameters of the particles were in the nm range, which may be due to the presence of the surfactant in the interlamellar space. The surfactant cations swell the layer spacing so that the particles have more chance to disperse over a wide space and also prevented agglomeration.

The TEM of platinum intercalated in hectorite (Pt-CTA-Hec 1 and Pt-CTA-Hec 2) are shown in Fig. 5. This figure indicated that the particle size was similar to that of $\mathrm{Pt}$ intercalated in montmorillonite but the dispersion of the particles was poor when compared to the Pt-CTA-MM catalysts. TEM images (Fig. 5) showed that the particle size of $\mathrm{Ru}$ in the $\mathrm{Ru}$-hectorite catalysts was larger than in the

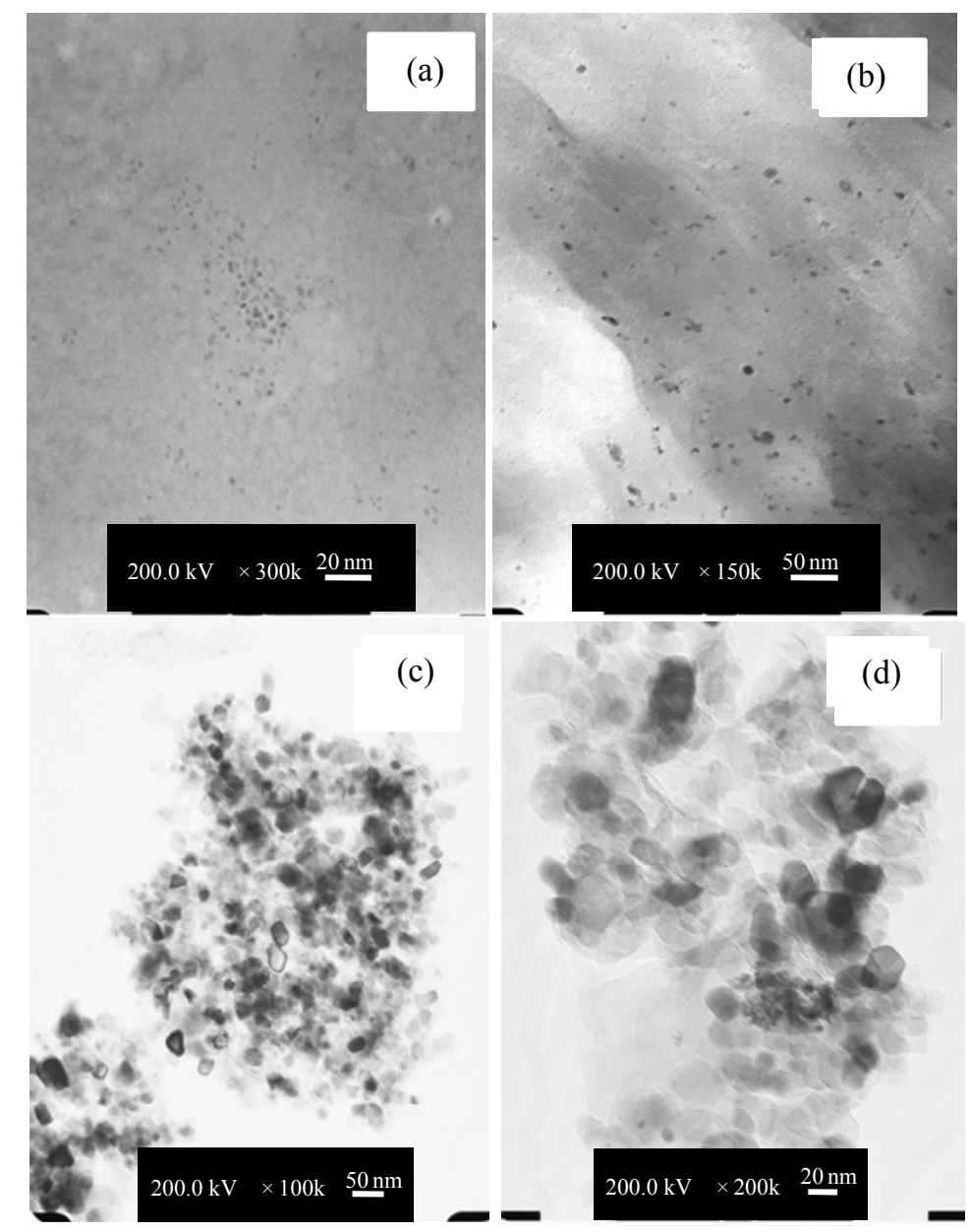

Fig. 4. Transmission electron micrographs of Pt-CTA-MM 1 (a), Pt-CTA-MM 2 (b), Ru-CTA-MM 1 (c), and Ru-CTA-MM 2 (d). 
Ru-montmorillonite catalysts. This increase in particle size may be due to the lesser swelling of hectorite compared to montmorillonite.

\subsubsection{AAS analysis}

The catalysts samples were subjected to AAS analysis to determine the actual metal content in the clay minerals. The results reported in Table 1 indicated that the actual metal contents of the catalysts were almost equal to the nominal amounts.

\subsubsection{BET surface area analysis}

The surface area of the different smectite clay minerals used as support materials and the metal loaded clay catalysts are given in Table 1. It was observed that the surface area decreased when the clay minerals were intercalated with the bulky surfactant cations. This was because of the inaccessibility of the adsorbate nitrogen molecules into the interlamellar space due to the presence of the bulky organic cations [36]. The increase in the surface area of the metal loaded catalysts was due to the adsorption of nitrogen molecules on metallic sites also.
Table 1 Physico-chemical properties of the catalysts

\begin{tabular}{lccc}
\hline Material & Metal content $(\mathrm{wt} \%)$ & $A_{\mathrm{BET}} /\left(\mathrm{m}^{2} / \mathrm{g}\right)$ & $d_{\mathrm{ave}} / \mathrm{nm}$ \\
\hline Na-Montmorillonite & \multicolumn{3}{c}{208.7} \\
CTAM & 0.98 & 90.5 & \\
Pt-CTA-MM 1 & 1.97 & 128.9 & 2.7 \\
Pt-CTA-MM 2 & 0.89 & 112.5 & 11.2 \\
Ru-CTA-MM 1 & 1.98 & - & 21.7 \\
Ru-CTA-MM 2 & - & 47.13 & - \\
Li-Hec & - & 34.21 & - \\
CTA-Hec & 0.92 & 40.68 & 2.3 \\
Pt-CTA-Hec 1 & 1.68 & - & 9.5 \\
Pt-CTA- Hec 2 & 0.93 & 41.81 & 21.3 \\
Ru-CTA- Hec 1 & 1.85 & - & 24.5 \\
Ru-CTA- Hec 2 & &
\end{tabular}

\subsection{Selective hydrogenation of crotonaldehyde, cinnamaldehyde, and citral}

Catalytic reaction experiments were carried out in a microreactor (vapor phase) equipped with an online gas chromatographic system. In each experiment $0.1 \mathrm{~g}$ of reduced catalyst (Pt-CTA-MM 1, Pt-CTA-MM 2, Ru-CTA-MM 1, Ru-CTA-MM 2, Pt-CTA-Hec 1, Pt-CTA-Hec 2, Ru-CTAHec 1, or Ru-CTA-Hec 2) was preactivated in flowing hy-

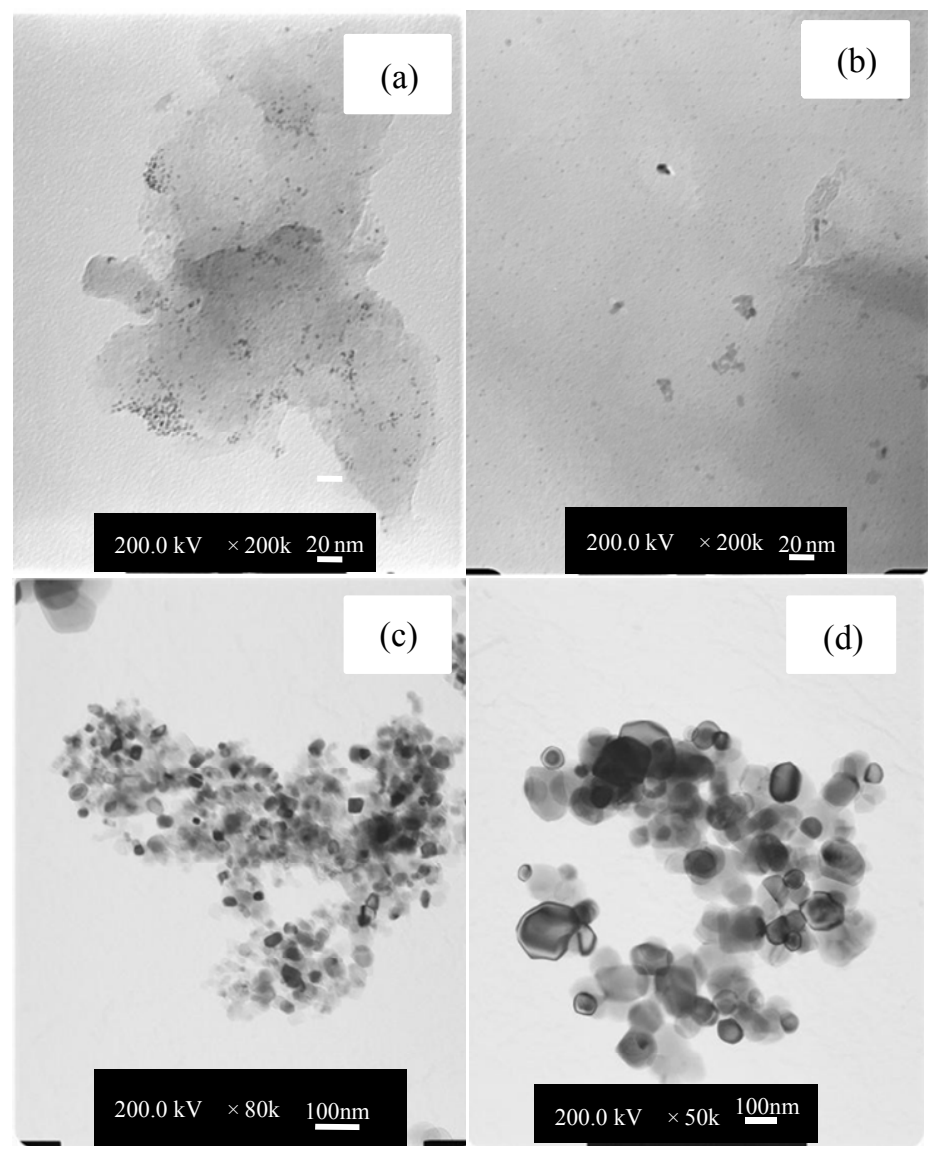

Fig. 5. Transmission electron micrographs of Pt-CTA-Hec 1 (a), Pt-CTA- Hec 2 (b), Ru-CTA- Hec 1 (c), and Ru-CTA- Hec 2 (d). 
drogen $(40 \mathrm{ml} / \mathrm{min})$ at $200{ }^{\circ} \mathrm{C}$ for $1 \mathrm{~h}$. The catalytic activity was evaluated by injecting $1.0 \mu \mathrm{l}$ of crotonaldehyde or cinnamaldehyde or citral at different temperatures. The comparison of the catalytic activity of the intercalated montmorillonite and hectorite catalysts was made. It showed the effect of host material on conversion and selectivity towards the corresponding $\alpha, \beta$-unsaturated alcohols.

\subsubsection{Effect of temperature}

The reaction temperature was varied from $100{ }^{\circ} \mathrm{C}$ to 200 ${ }^{\circ} \mathrm{C}$ in steps of $25^{\circ} \mathrm{C}$ at a constant flow rate of hydrogen $(40$ $\mathrm{ml} / \mathrm{min}$ ) over $0.1 \mathrm{~g}$ of Pt-CTA-MM 1 and Ru-CTA-MM 1 catalysts. The conversion of crotonaldehyde (CRAL) increased as the temperature of the reaction increased (Fig. 6 (a) and (b)). This was because metallic sites at higher temperatures gave more adsorption of the reactant, namely, crotonaldehyde, which resulted in increased conversion. As the temperature increased, the selectivity for crotyl alcohol (CROH) decreased over Pt-CTA-MM 1 (Fig. 6(a)). A similar observation was made by Englisch et al. [39]. This decrease in selectivity with temperature may be due to either the isomerization of crotyl alcohol into butyraldehyde or the consecutive hydrogenation of crotyl alcohol to yield butyl alcohol at higher temperatures. Also, the observed selectivity $(31 \%)$ of crotyl alcohol over Pt-CTA-MM 1 was better than that with the same amount $(1 \mathrm{wt} \%)$ of Pt catalysts loaded on $\mathrm{CeO}_{2}$ and reduced at $473 \mathrm{~K}$, which showed no more than 5\% selectivity [40]. Even with the very low metal content, the preferred formation of $\mathrm{Pt}(111)$ particles in the Pt-CTA-MM 1 catalyst may make the catalyst more selective towards $\mathrm{C}=\mathrm{O}$ hydrogenation, which is less favored in ceria supported catalysts. The intercalated ruthenium catalyst (Ru-CTA-MM 1) also exhibited the same trend of catalytic activity (Fig. 6(b)) to that of the intercalated Pt catalysts. The conversion at $100{ }^{\circ} \mathrm{C}$ was about $19 \%$, which increased linearly as the temperature increased and reached a maximum of $87 \%$ at $200{ }^{\circ} \mathrm{C}$. The selectivity for crotyl alcohol over the intercalated Ru catalysts was comparatively low when compared to Pt-CTA-MM 1. This may be due to the adsorption at the $\mathrm{C}=\mathrm{C}$ bond followed by hydrogenation, which is more favorable over the ruthenium particles than $\mathrm{C}=\mathrm{O}$ hydrogenation because of its smaller $d$ orbital and the larger particle size of ruthenium compared to platinum [41].

As the selectivity is influenced by the presence of substituents on the $\mathrm{C}=\mathrm{C}$ bond, studies were conducted with a reactant containing a phenyl group on the $\mathrm{C}=\mathrm{C}$ bond, that is, cinnamaldehyde (CAL). The hydrogenation of cinnamaldehyde was carried out over all the catalysts using the same microreactor (vapor phase) connected to a gas chromatograph. Data obtained in the hydrogenation of cinnamaldehyde over Pt-CTA-MM 1 and Ru-CTA-MM 1 catalysts are

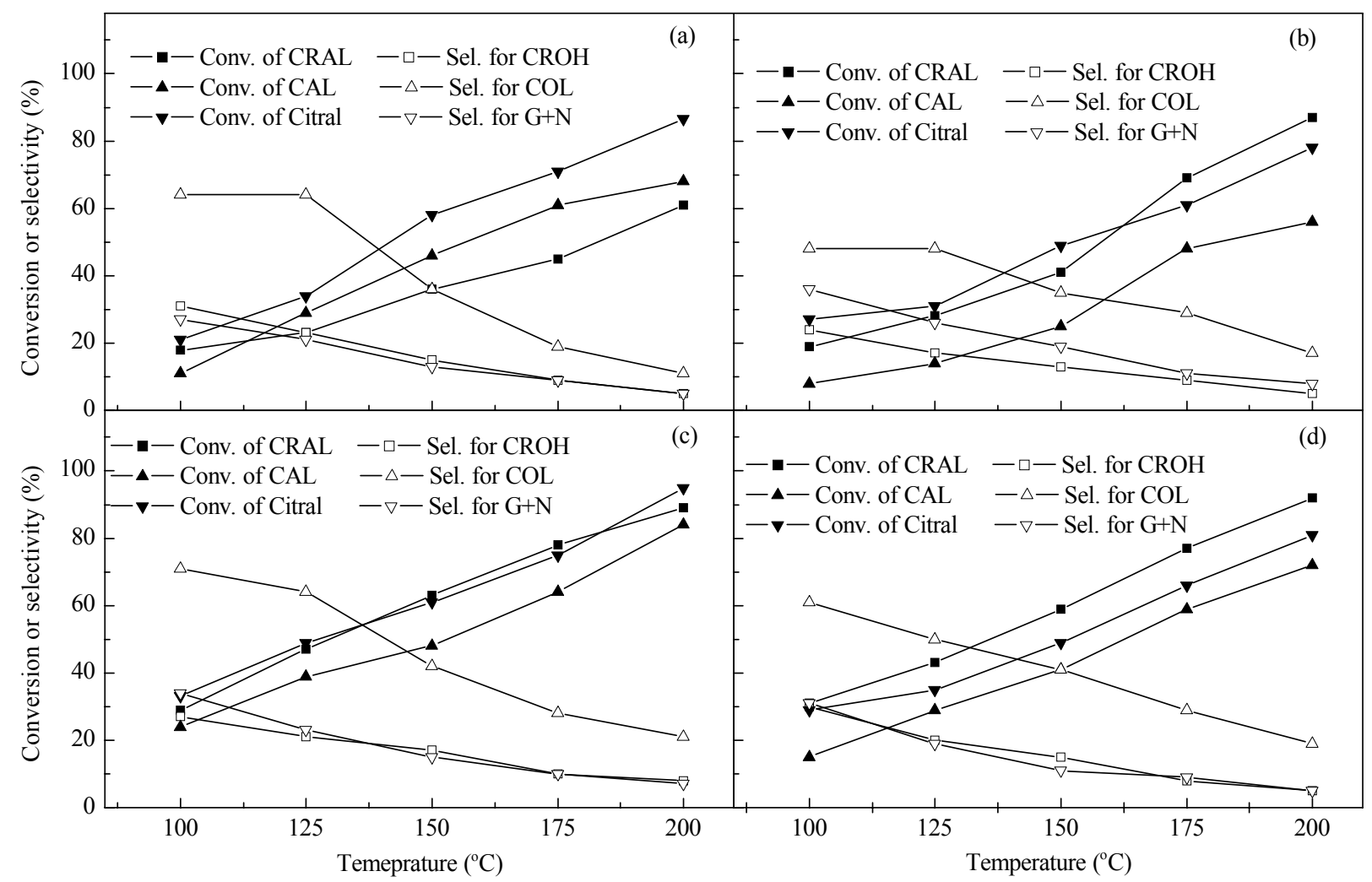

Fig. 6. Effect of temperature on conversion and selectivity over Pt-CTA-MM 1 (a), Ru-CTA-MM 1 (b), Pt-CTA-MM 2 (c), and Ru-CTA-MM 2 (d) catalysts. Mass of catalyst: $0.1 \mathrm{~g}$; hydrogen flow rate: $40 \mathrm{ml} / \mathrm{min}$. 
shown in Figs. 6(a) and (b). Again, the temperature played a vital role in both the activity and selectivity for cinnamyl alcohol (COL). As the temperature increased, the conversion increased linearly. A remarkable conversion of $84 \%$ was obtained with the Pt-CTA-MM 2 catalyst at $200{ }^{\circ} \mathrm{C}$. This was because of the higher reactivity of hydrogen on the platinum surface than on the other noble metals [42]. The steric effect due to the bulky phenyl group and the temperature of the reaction altered the selectivity significantly. Even though the bulky phenyl group was present in cinnamaldehyde, a high temperature favored the consecutive hydrogenation and resulted in some amount of hydrocinnamyl alcohol and less selectivity for cinnamyl alcohol.

The conversion of citral into the hydrogenated products was found to be comparatively higher than the conversion obtained for crotonaldehyde or cinnamaldehyde hydrogenation over both Pt-CTA-MM 1 and Ru-CTA-MM 1. This was due to the presence of more reducible functionalities in the citral molecule. At high temperature, less selectivity for the desired products, namely, geraniol and nerol $(\mathrm{G}+\mathrm{N})$, was obtained over these catalysts due to consecutive hydrogenation and isomerization.

The effect of temperature on the catalytic activity and selectivity of Pt and $\mathrm{Ru}$ intercalated in hectorite (Pt-CTA-Hec 1 and Ru-CTA-Hec 1) was also evaluated with the hydrogenation of the three different $\alpha, \beta$-unsaturated aldehydes.
The results are reported in Figs. 7(a) and (b). As observed with the other catalysts, the conversion of the different aldehydes into hydrogenated products over Pt and Ru intercalated in hectorite increased and the selectivity for the corresponding unsaturated alcohols decreased when the temperature was increased.

In order to establish the effect of the host material on selectivity for the unsaturated alcohol, the data obtained at $150{ }^{\circ} \mathrm{C}$ for all the catalysts was compared. The metal loaded in montmorillonite showed better selectivity than the metal loaded in hectorite. This difference in selectivity may be due to the presence of higher acidity in montmorillonite compared to hectorite. The higher selectivity was due to Lewis acid sites located in the vicinity of the metal [20]. The carbonyl oxygen is able to adsorb on the Lewis acid sites, so that the simultaneous adsorption of $\mathrm{C}=\mathrm{C}$ and $\mathrm{C}=\mathrm{O}$ does not occur. Also, the reactant structure and presence of substituents in the $\mathrm{C}=\mathrm{C}$ bond may have some influence on the selectivity of the catalyst for the formation of corresponding unsaturated alcohol.

\subsubsection{Effect of metal loading}

The data obtained in the hydrogenation of crotonaldehyde, cinnamaldehyde, and citral at different temperatures over Pt-CTA-MM 2, Ru-CTA-MM 2, and Pt-CTA-Hec 2,

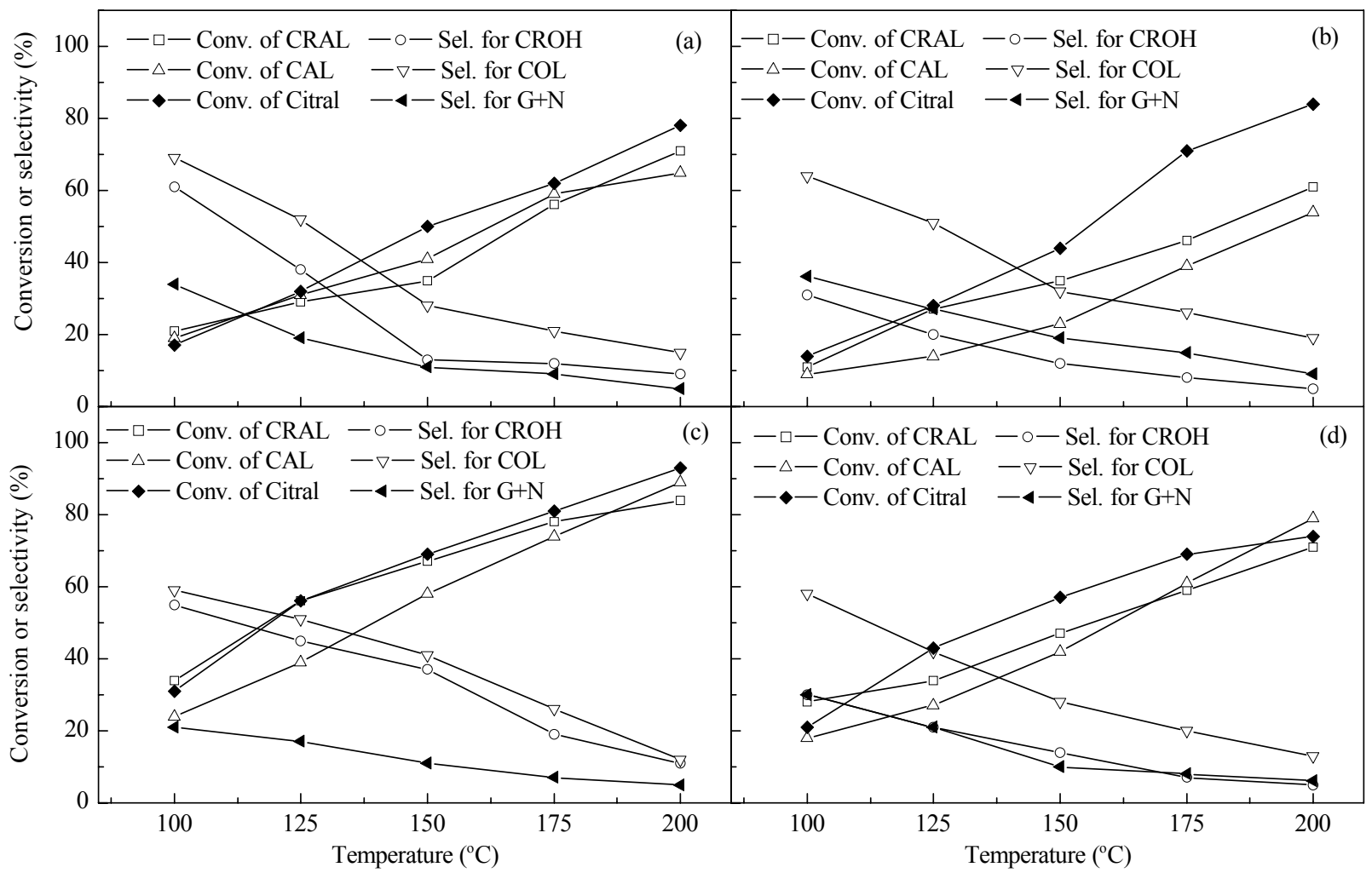

Fig. 7. Effect of temperature on conversion and selectivity over Pt-CTA-Hec 1 (a), Ru-CTA- Hec 1 (b), Pt-CTA- Hec 2 (c), and Ru-CTA- Hec 2 (d) catalysts. Mass of catalyst: $0.1 \mathrm{~g}$; hydrogen flow rate: $40 \mathrm{ml} / \mathrm{min}$. 
Ru-CTA-Hec 2 are plotted in Fig. 6(c), (d), and Fig. 7(c), (d), respectively. The results indicated that as the metal loading increased, conversion increased due to the availability of more catalytic sites. However a slight decrease in selectivity was observed with $2 \mathrm{wt} \%$ metal loaded catalysts, which may be due to the presence of larger sized metal particles.

\subsubsection{Effect of hydrogen flow rate}

In this vapor phase hydrogenation reaction, hydrogen gas was used as reactant as well as carrier gas. Therefore, a change in the flow rate of hydrogen alters the partial pressure of hydrogen and also the contact time of the reactant in the catalyst bed, which may lead to a significant change in the yield and selectivity. Englisch et al. [39] observed significant changes in the conversion and selectivity in the vapor phase hydrogenation of crotonaldehyde with different partial pressures of hydrogen. Thus, in this study, the hydrogenation of crotonaldehyde, cinnamaldehyde, and citral at different hydrogen flow rates between $20-80 \mathrm{ml} / \mathrm{min}$ over representative catalysts, namely, Pt-CTA-MM 1, Ru-CTAMM 1, Pt-CTA-Hec 1, and Ru-CTA-Hec 1, were carried out to find out the influence of hydrogen flow rate on the conversion and selectivity. The reactant $(1.0 \mu \mathrm{l})$ was injected onto the catalyst in the microreactor at $150{ }^{\circ} \mathrm{C}$. The data obtained in the hydrogenation of various unsaturated aldehydes at different flow rates are shown in Fig. 8.

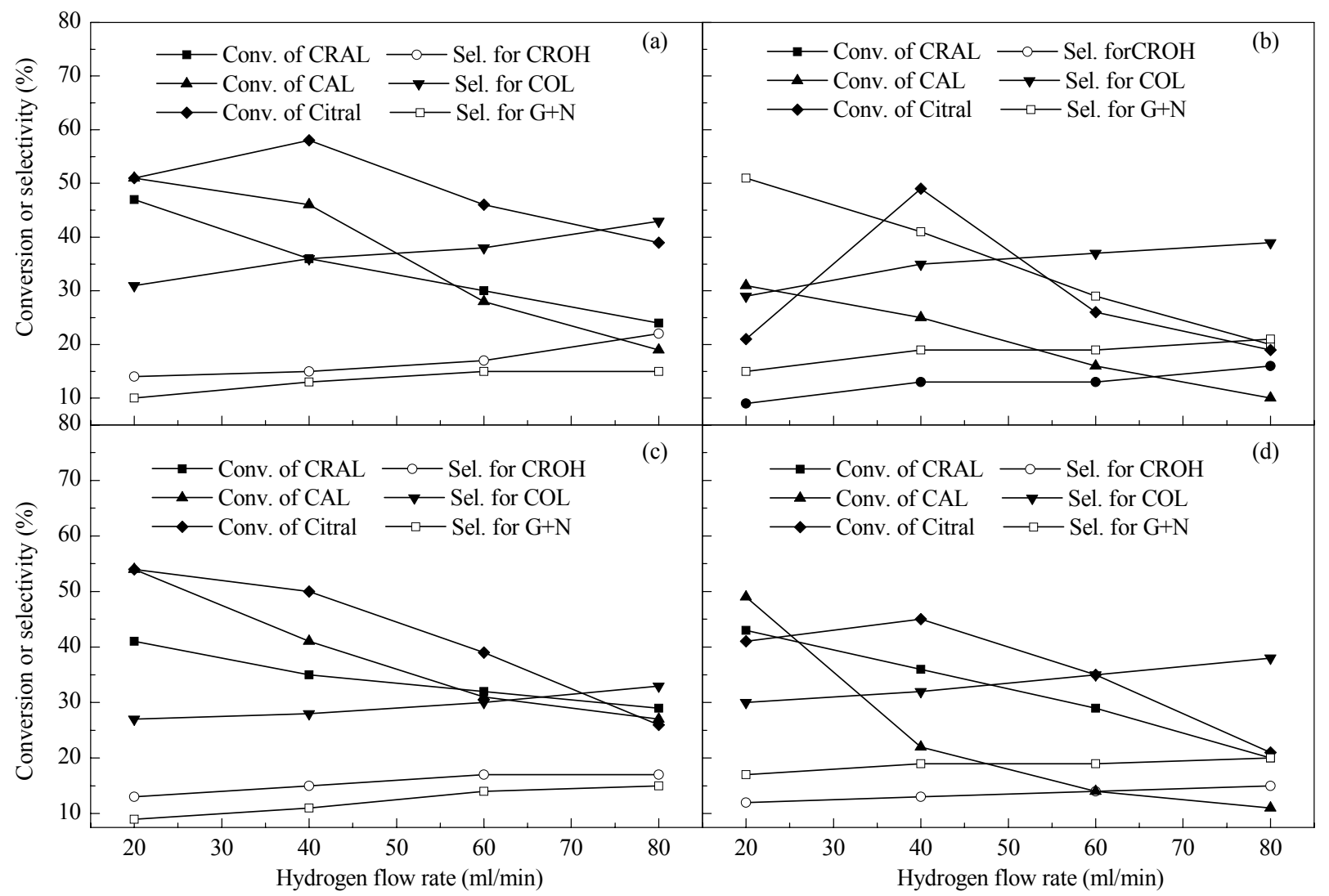

Fig. 8. Effect of hydrogen flow rate on conversion and selectivity over Pt-CTA- MM 1 (a), Ru-CTA-MM 1 (b), Pt-CTA-Hec 1 (c), and Ru-CTA-Hec 1 (d) catalysts. Mass of catalyst: $0.1 \mathrm{~g}$; temperature: $150^{\circ} \mathrm{C}$.

The flow rate of hydrogen has a strong influence on the conversion of different unsaturated aldehydes and also on the distribution of the products in the hydrogenation. The increase in hydrogen flow rate increased the partial pressure of hydrogen and thus decreased the contact time which decreased conversion. The selectivity for the corresponding unsaturated alcohols increased when the flow rate of hydrogen increased. This indicated that the selectivity was not only controlled by the properties of the active sites but also by the pressure of hydrogen $[43,44]$.

\section{Conclusions}

Intercalation of nano-particles of noble metals in clay minerals by the micellar technique was used to disperse the nano-particles in the interlamellar region of the clay material. TEM micrographs of the intercalated metal catalysts confirmed that the dispersion of the particles was good and had sizes in the $\mathrm{nm}$ range $(1-25 \mathrm{~nm})$. Due to higher swelling capacity of montmorillonite than hectorite, a better dispersion of metal particles was obtained with the former. The 
vapor phase hydrogenation of unsaturated aldehydes showed that almost all the catalysts showed comparable catalytic activity under the same conditions. The increased selectivity of the metal catalysts intercalated in montmorillonite than in hectorite was due to the higher acidity of the former. The observed increase in selectivity for $\alpha, \beta$-unsaturated alcohol with increase in flow rate of hydrogen showed that the selectivity was not only controlled by the active sites but also by the partial pressure of hydrogen. The hydrogenation of $\alpha, \beta$-unsaturated aldehydes over these synthesized catalysts indicated that they can be used as the catalysts for many other hydrogenation reactions.

\section{References}

1 Boutonnet M, Kizling J, Stenius P, Maire G. Colloid Surf, 1982, 5: 209

2 Nakahira T, Graetzel M. J Phys Chem, 1984, 88: 4006

3 Halperin W P. Rev Mod Phys, 1986, 58: 533

4 Nashner M S, Frenkel A I, Adler D L, Shapley J R, Nuzzo R G. J Am Chem Soc, 1997, 119: 7760

5 Schmid G, West H, Mehle H, Lehnert A. Inorg Chem, 1997, 36: 891

6 Henglein A. J Phys Chem, 1993, 97: 5457

7 Toshima N, Yonezawa T, Kushihashi K. J Chem Soc, Faraday Trans, 1993, 89: 2537

8 Duff D G, Baiker A, Edwards P P. Langmuir, 1993, 9: 2301

9 Glavee G N, Klabunde K J, Sorensen C M, Hadjipanayis G C. Langmuir, 1993, 9: 162

10 Liz-Marzan L M, Philipse A P. J Phys Chem, 1995, 99: 15120

11 Toshima N, Takahashi T. Bull Chem Soc Jpn, 1992, 65: 400

12 Petit C, Lixon P, Pileni M P. J Phys Chem, 1993, 97: 12974

13 Wilcoxon J P, Williamson R L, Baughman R. J Chem Phys, 1993, 98: 9933

14 Yu W Y, Liu H F, Liu M H, Tao Q. J Mol Catal A, 1999, 138: 273

15 Centomo P, Zecca M, Lora S, Vitulli G, Caporusso A M, Tropeano M L, Milone C, Galvagno S, Corain B. J Catal, 2005, 229: 283

16 Nakao Y, Kaeriyama K. J Colloid Inter Sci, 1989, 131: 186

17 Wang Y, Liu H F, Huang Y X. Polym Adv Technol, 1996, 7: 634

18 Wang Q, Liu H F, Wang H G. J Colloid Inter Sci, 1997, 190: 380
19 Szucs A, Berger F, Dekany I. Colloids Surf A, 2000, 174: 387

20 Kun I, Szollosi G, Bartok M. J Mol Catal A, 2001, 169: 235

21 Szollosi G, Torok B, Baranyi L, Bartok M. J Catal, 1998, 179: 619

22 Papp S, Szucs A, Dekany I. Appl Clay Sci, 2001, 19: 155

23 Sivakumar T, Mori T, Kubo J, Morikawa Y. Chem Lett, 2001, 30: 860

24 Sivakumar T, Krithiga T, Shanthi K, Mori T, Kubo J, Morikawa Y. J Mol Catal A, 2004, 223: 185

25 Mastalir A, Kiraly Z, Szollosi G, Bartok M. J Catal, 2000, 194: 146

26 Mastalir A, Kiraly Z, Szollosi G, Bartok M. Appl Catal A, 2001, 213: 133

27 Maki-Arvela P, Hajek J, Salmi T, Murzin D Y. Appl Catal A, 2005, 292: 1

28 Shirai M, Tanaka T, Arai M. J Mol Catal A, 2001, 168: 99

29 Milone C, Crisafulli C, Ingoglia R, Schipilliti L, Galvagno S. Catal Today, 2007, 122: 341

30 Manikandan D, Divakar D, Valentine Rupa A, Revathy S, Esther Leena Preethi M, Sivakumar T. Appl Clay Sci, 2007, 37: 193

31 Divakar D, Manikandan D, Rupa V, Preethi E L, Chandrasekar R, Sivakumar T. J Chem Technol Biotechnol, 2007, 82: 253

32 Coloma F, Sepulveda-Escribano A, Fierro J L G, RodriguezReinoso F. Appl Catal A, 1996, 148: 63

33 Consonni M, Jokic D, Murzin D Y, Touroude R. J Catal, 1999, 188: 165

34 Reyes P, Aguirre M C, Pecchi G, Fierro J L G. J Mol Catal A, 2000, 164: 245

35 Kiraly Z, Veisz B, Dekany I, Mastalir A, Razga Z. Chem Commun, 1999: 1925

36 Kiraly Z, Veisz B, Mastalir A, Kofarago G. Langmuir, 2001, 17: 5381

37 Manikandan D, Divakar D, Sivakumar T. Catal Lett, 2008, 123: 107

38 Manikandan D, Divakar D, Sivakumar T. Catal Commun, 2007, 8: 1781

39 Englisch M, Jentys A, Lercher J A. J Catal, 1997, 166: 25

40 Abid M, Paul-Boncour V, Touroude R. Appl Catal A, 2006, 297: 48

41 Gallezot P, Richard D. Catal Rev-Sci Eng, 1998, 40: 81

42 Masel R I. Principles of Adsorption and Reaction on Solid Surfaces. New York: Wiley, 1996

43 Claus P. Top Catal, 1998, 5: 51

44 Yamada H, Urano H, Goto S. Chem Eng Sci, 1999, 54: 5231 